\title{
The Usefulness of Birth Weight Z-Score as a Predictor of Catch Up Growth in Preterm Infants
}

Huee Jin Park, M.D. ${ }^{* \dagger}$, Hae Yun Lee, M.D. ${ }^{* \dagger}$, Hae Kyung Woo, M.D. ${ }^{*,}$, Seon Nyo Kim, M.D. ${ }^{* \dagger}$, Juyoung Lee, M.D.* , Hye Ran Yang, M.D.*, , Beyong Il Kim, M.D.*, , and Chang Won Choi, M.D.,*

Department of Pediatrics*, Seoul National University Bundang Hospital, Seongnam, Korea Department of Pediatrics ${ }^{\dagger}$, Seoul National University Children's Hospital, Seoul, Korea

Department of Pediatrics ${ }^{\ddagger}$, Seoul National University College of Medicine, Seoul, Korea

\section{ABSTRACT}

Purpose: The aim of the study was to examine whether the degree of fetal smallness in small for gestational age (SGA) infants would increase the risk of catch-up-growth failure at 12 and 24 months corrected age (CA), and whether the high-calorie nutritional support would improve catch-up growth between 12 and 24 months CA.

Methods: We conducted a retrospective cohort study on 103 preterm infants born between January 2010 and December 2011. Logistic regression analysis was performed to investigate whether the birth weight $\mathrm{z}$-score would be an independent risk factor for catch-up growth failure at 12 or 24 months CA. Among the 46 infants with failed catch-up growth at 12 months CA, 16 infants were provided high-calorie nutritional support, including nutritional supplements and medium chain triglyceride (MCT) oil at the pediatric gastroenterology clinic.

Results: Of 103 preterm infants, 34 infants (33\%) were SGA and 69 infants (67\%) were appropriate for gestational age (AGA). One birth weight z-score decrement increased the odds for catch-up growth failure 2.9 times at 12 months CA and 3.0 times at 24 months CA after adjustment for major neonatal morbidities. The increase in z-score between 12 and 24 months CA was significantly greater in the infants provided nutritional support than in the infants who were not provided nutritional support. Conclusion: The birth weight z-score can be used as a predictor of catch-up growth failure. High-calorie nutritional support may improve weight gain during the second year in preterm infants with failed catch-up growth at 12 months CA.

Key Words: Small for gestational age, Preterm, Catch up growth, Z-score, High calorie nutritional support

\section{서론}

최근 신생아학의 발전과 의료 기술의 발달로 미숙아 사망률이 감소하고, 성장과 발달에 대
Received: 19 June 2015

Revised: 28 July 2015

Accepted: 5 August 2015

Correspondence to:

Chang Won Choi, M.D., Ph.D., Department of Pediatrics, Seoul National University Bundang Hospital, 82, Gumi-ro 173 beongil, Bundang-gu, Seongnam 13620, Korea

Tel: +82-31-787-7286

Fax: +82-2-787-4054

E-mail: choicw@snu.ac.kr

Copyright(c)

By Korean Society of Neonatology.

All right reserved.

This is an Open-Access article distributed under the terms of the Creative Commons Attribution Non-Commercial License (http://creativecommons.org/licenses/ by-nc/3.0), which permits unrestricted non-commercial use, distribution, and reproduction in any medium, provided the original work is properly cited. 
한 예후가 향상되면서 신생아 집중 치료실 퇴원 이후의 미숙아의 성장 및 발달에 대한 관심이 증가하고 있다1). 미숙아는 만삭아에 비해 신생아 호흡 곤란 증후군, 뇌실 내 출혈, 신생아 괴사성 장염 과 같은 합병증의 발생률이 매우 높으며, 이러한 합병증이 있는 경 우에는 일정 기간 동안 성장 지연이 동반되고, 이후 회복기를 거친 후 체중 증가가 시작된다2.3.) 따라서 미숙아들이 신생아 집중 치료 실에서 퇴원한 이후에도 성장에 대한 지속적인 관찰이 필요하고, 성장 지연이 있는 경우에는 이를 중요한 건강 문제로 인식하고 필 요 시 고열량 영양 보조를 통한 영양 개입을 함으로써 따라 잡기 성장을 이룰 수 있게 하는 노력이 필요하다.

현재까지 부당 경량아(small for gestational age, SGA)와 적정 체중아(appropriate for gestational age, AGA)들을 대상으로 한 따라 잡기 성장에 관련된 연구들에서는 상충하는 결과들이 보고 되었다 ${ }^{2-8)}$. SGA는 출생 시 영아의 크기와 관련된 용어로, 출생 체중 혹은 출생 키가 해당 재태 연령의 환자에 비해 2 표준 편차(standard deviation, SD) 이하, 혹은 10 백분위 수(percentile) 이하일 때로 정의된다. SGA로 출생하게 되는 원인에는 염색체 이상, 자궁 내 감염, 모체의 질환, 태반 기능 이상, 모체의 흡연, 다태아 임신 등이 알려진 요소이나, 대부분의 경우 원인이 밝혀지지 않은 경우 가 많단). 일반적으로 기저 질환이 없는 만삭 SGA는 출생 후 따 라 잡기 성장을 한다는 것으로 알려져 있다4,6). 일부 연구들에서 는 SGA로 출생한 경우 약 $46 \%$ 에서 3세가 될 때까지 AGA에 비해 체중이 작다고 보고하였고1), SGA로 출생한 경우 성인 키까지도 작을 수 있다는 것이 알려져 있어 성장 호르몬 치료가 고려되기도 한다2,9,10). Knops 등은 32주 미만으로 출생한 미숙아가 10세가 되 었을 때 $\mathrm{AGA}$ 에서는 성장 지연이 없었으나, SGA로 출생한 경우에 는 성장 지연을 보인다고 보고하였으며, 출생 초기의 체중 증가 여 부가 향후 청소년기까지의 성장에 중요한 예후 인자라고 밝혔다1)

또한, 자궁 내 성장 지연이 있던 SGA의 경우 성인기에 심혈관계 질환과 대사 증후군에 이환될 가능성이 높다고 보고한 연구들이 있다 ${ }^{2-14)}$. 이는 자궁 내 성장 지연 즉 SGA로 출생한 것이 영유아기 를 넘어 성인기의 건강 상태에까지 장기적인 영향을 미침을 시사 한다 ${ }^{14)}$.

그러나 현재까지의 연구들 중에서 미숙아 SGA의 따라 잡기 성 장에 출생 시 체중의 적은 정도가 미치는 영향을 분석한 연구는 드물었다.

따라서, 본 연구에서는 미숙아 중 SGA에서 임신 나이에 비해 체 중이 적게 나가는 정도, 즉 출생 체중의 Z 점수를 계측하여, 저체 중의 정도가 심할수록, 즉 출생 체중의 $\mathrm{Z}$ 점수가 낮을수록 교정 12 개월 또는 24 개월까지 따라 잡기 성장에 실패할 가능성이 높아 질 것이다라는 가설을 검정하고자 하였다. 또한 따라 잡기 성장에 실패한 환자에서 고열량 영양 보조를 해주었을 때 따라 잡기 성장 이 개선되는지 알아보고자 하였다.

\section{대상 및 방법}

\section{1. 대상}

2010년 1월 1일부터 2011년 12월 31일까지 분당서울대학교병원 에서 출생하여 신생아 집중 치료실에 입원하였던 임신나이 34 주 미만 미숙아 162 명 중에서 1) 입원 기간 중 사망한 3명, 2) 교정 나 이 12 개월을 지나서까지 추적관찰이 되지 않았던 48 명, 3) 출생 후 성장에 상당한 영향을 미칠 것으로 생각되는 조건들을 갖고 있 던 미숙아들15,16), 즉 괴사성 장염으로 장 절제 수술을 받았던 4명, 기관 절개 후 가정용 인공호흡기를 가지고 퇴원한 2 명과 염색체 이 상 또는 주요 선천성 기형이 확인된 2 명을 제외한 103명이 최종 연 구대상이었다.

\section{2. 자료 수집 방법}

최종 연구대상 103명 중에서 SGA는 34명(33\%), AGA는 69명 (67\%)이었다. 출생 후 교정 나이 12 개월과 24 개월의 체중과 Z 점 수를 조사하였고, 환자와 산모의 인구학적 및 임상적 특성들에 대 한 정보들은 전자 의무 기록으로부터 수집되었다. 출생 체중의 Z 점수는 2013년에 발표된 Fenton 성장 곡선 및 LMS 값을 기준으로 산정하였고 ${ }^{1718)}$, 교정 나이 12 개월과 24 개월의 체중의 Z 점수는 세 계 보건 기구(World Health Organization, WHO)에서 2006년에 발표한 성장 도표 및 LMS 값을 이용하여 산정하였다18,19)

미숙아를 대상으로 재태 주령에 따른 출생 시 체중의 LMS 값에 대해서는 Fenton 성장 도표가 보편적으로 사용되는 자료이며, 교 정 12 개월 24 개월째의 체중 Z 점수의 비교에서도 마찬가지로 $\mathrm{WHO}$ 기준을 사용하는 것이 일관성이 있어, 본 논문에서는 Fenton 성장 곡선 및 WHO 성장 도표를 사용하였다.

$\mathrm{SGA}$ 는 출생 체중이 해당 임신 나이에서 2 표준 편차 이하 경우 로, 미숙아의 따라 잡기 성장(catch up growth) 실패는 WHO 2006년 성장 곡선을 기준으로 교정 나이 12개월 또는 24개월에서 체중이 2 표준 편차 이하인 경우로 정의하였다 ${ }^{20)}$.

조사한 미숙아들에 대한 정보로는 1) 인구학적 정보로, 분만 당 시 산모의 나이, 미숙아의 임신 나이, 출생 체중, 출생 신장, 성별, 다태아 여부, 자궁 내 성장 지연여부, 2) 미숙아 관련 합병증으로, 신생아 호흡곤란증후군(respiratory distress syndrome, RDS), 기관지 폐 이형성증(bronchopulmonary dysplasia, BPD), 신생 아 괴사성 장염(necrotizing enterocolitis, NEC) 여부, 3) 따라 잡 기 성장에 실패한 성장 장애군을 대상으로 소아소화기영양분과 의 외래 추적 관찰을 받는지 여부를 조사하였으며, 외래 추적 관 찰 동안 체중, 키, 두위 및 이유식 섭취 정도, 식이 습관, 열량 보충 제, 중쇄 지방산 및 비타민 보충 여부, 신생아 집중 치료실 퇴원 이 후 5일 이상 입원력이 있는지 여부를 조사하였다. 
기관지 폐 이형성증은 교정 나이 36주에도 산소를 필요로 하는 경우로 하였고, 신생아 괴사성 장염은 modified Bell's staging criteria stage 2 이상인 경우로 하였고 장 절제술을 받지 않은 경 우만을 연구 대상으로 하였다.

소화기 영양 분과 추적 관찰을 하면서 시행한 구체적인 영양 지 원 내용은 1) 목표 칼로리를 $120 \mathrm{cal} / \mathrm{kg} / \mathrm{day}$ 로 하였고, 2) 교정 연령 12개월까지는 탄수화물 다당체(Maxijul ${ }^{\circledR}$, SHS International, Liverpool, UK) 및 중쇄 지방산(MCT oil, Medium chain triglyceride oil) 을 분유 또는 모유에 추가하였고, 3) 교정 6개월 부터는 이유식을 섭취하도록 권장하였고, 4) 이유식 섭취에 대한 개별적인 영양 상담을 시행하였으며, 5) 교정 연령 12 개월부터 24 개월 사이에는 영양 보충제(페디아파우더 ${ }^{\circledR}$, (주)엠디웰아이엔씨, 또 는 PediaSure ${ }^{\circledR}$, Abbott Laboratories, Zwolle, Netherlands)을 제공하였다. 종합 비타민 시럽제(Alvityl, Latema, France), 철분제 (Ferrumkid, Choongwae Pharma, Co., Ltd.), 비타민 D 시럽제 는 영양 지원군과 비지원군 모두에서 교정 연령 12 개월까지 복용 하였다.

이 연구는 분당서울대학교병원 연구윤리위원회(institutional review board, IRB)의 승인을 받았으며(B-1503/292-114), 의무 기록을 통한 후향적 연구이어서 동의서는 면제되었다.

\section{3. 통계 분석}

수집된 자료에 대한 통계적 분석은 SPSS Version 21.0 (SPSS Inc., Chicago, IL, USA) 을 이용하였다. 교정 나이 12개월 또는 24 개월 시점에서 따라 잡기 성장에 영향을 주는 인자를 비교하기 위 해 로지스틱 회귀 분석을 시행하였다. 출생 시 체중이 작을수록 교정 12 개월 또는 24 개월에서도 체중이 작을 것이라는 가설을 검 증하기 위해 출생 시 체중 Z 점수와 교정 12 개월 또는 24 개월에서 의 체중의 Z 점수간 선형 회귀 분석을 시행하였다. 성장 지연군에 서 고열량 영양 보조가 교정 나이 12 개월과 24 개월 사이의 체중 증가에 영향을 줄 것이라는 가설을 검증하기 위해 반복 분산 측도 (repeated ANOVA) 분석을 시행하였다. $P$-value 가 0.05 미만인 경우를 통계적으로 유의한 것으로 하였다.

\section{결과}

\section{1. 환자의 출생 후 성장}

103 명의 전체 미숙아 환자 중에서 SGA군의 출생 체중은 1,132 $\pm 311 \mathrm{~g}$ 이었으며, $\mathrm{AGA}$ 군의 출생 체중은 $1,462 \pm 504 \mathrm{~g}$ 으로 두 군 간에는 통계적으로 유의한 차이가 있었다 $(P<0.001) . \mathrm{SGA}$ 군과 $\mathrm{AGA}$ 군 간에 $\mathrm{BPD}$ 와 장절제술을 받지 않은 $\mathrm{NEC}$ 의 발생 빈도, 임 신 나이, $100 \mathrm{~mL} / \mathrm{kg} / \mathrm{day}$ 이상의 경구영양 도달 일수와 입원 기간
의 유의한 차이는 없었다.

반면 교정 나이 12 개월과 24 개월에서 따라 잡기 성장 실패의 빈 도는 각각 SGA군에서 70.6\%와 67.9\%, AGA군에서 29.4\%와 21.8 $\%$ 로 12 개월과 24 개월 모두에서 SGA군에서 AGA군에 비해 유의 하게 높았다(Table 1, Figure 1).

\section{2. 산모의 임상적 특징}

분만 당시 산모의 평균 나이는 SGA군은 33.1⒊8세, AGA군은 $32.6 \pm 4.0$ 세로 통계적으로 유의한 차이는 없었다. 미숙아들의 출 생 체중에 영향을 줄 것으로 예상되는 산모의 특징들은 임신성 당 뇨, 양수 과소증, 임신성 고혈압과 다태아 임신 여부였으며, 이들 중 임신성 당뇨, 양수 과소증과 다태아 임신 여부는 두 군 간에 유 의한 차이가 없었다. 반면에 임신성 고혈압 여부는 SGA군에서는 $50 \%, \mathrm{AGA}$ 군에서는 $10.1 \%$ 로 두 군 간에 유의한 차이가 있었다 (Table 2).

\section{3. 교정 12 개월, 24 개월째 따라 잡기 성장에 영향을 주는 요인} 교정 12 개월과 24 개월에서 따라 잡기 성장에 실패에 영향을 주

Table 1. Characteristics of Infants

\begin{tabular}{lccc}
\hline Variables & SGA $(\mathrm{n}=34)$ & AGA $(\mathrm{n}=69)$ & $P$-value \\
\hline Birth weight (g) & $1,132 \pm 311$ & $1,462 \pm 504$ & $<0.001$ \\
Gestational age (wks) & $31^{+2}\left(2^{+3}\right)$ & $29^{+2}\left(3^{+1}\right)$ & 0.03 \\
Severe BPD & $6(17.6 \%)$ & $14(20.3 \%)$ & 0.724 \\
NEC without operation & $5(14.7 \%)$ & $3(4.3 \%)$ & 0.068 \\
Failure to thrive* & $22(64.7 \%)$ & $18(26.1 \%)$ & $<0.001$ \\
The days at feeding & $13.88 \pm 14.19$ & $14.69 \pm 15.24$ & 0.653 \\
$\quad 100 \mathrm{~mL} / \mathrm{kg}$ /day & & & \\
Days of hospitalization & $55.91 \pm 37.18$ & $54.76 \pm 35.52$ & 0.791
\end{tabular}

*failed catch-up growth, with weight $\mathrm{z}$-score below the 10th percentile at 12 or 24 months corrected age.

Abbreviations: SGA, small for gestational age; AGA, appropriate for gestational age; BPD, bronchopulmonary dysplasia; NEC, necrotizing enterocolitis.

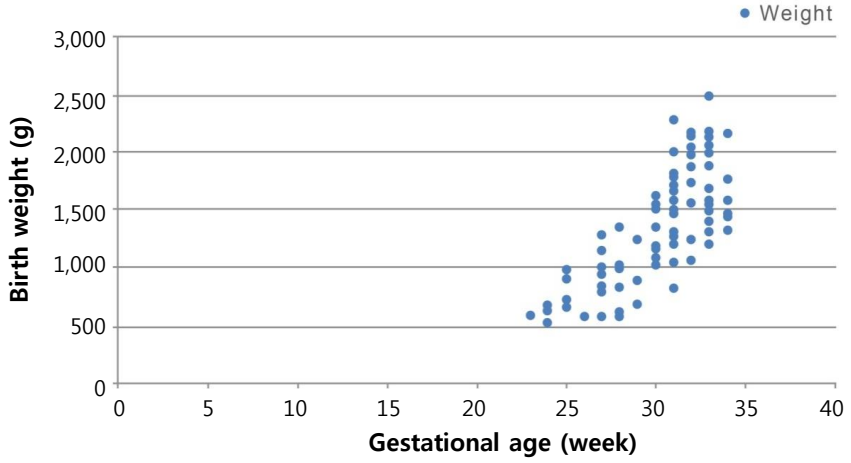

Figure 1. Scattergram of birth weight by gestational age. 
는 요인을 분석하기 위하여 출생 체중의 Z 점수, 신생아 집중 치료 실 입원 기간, 임신 나이, 산모의 나이, 다태아, 임신성 고혈압, $\mathrm{BPD}$ 및 장절제술을 시행하지 않은 괴사성 장염의 여부를 교란변 수(confounding variable)로서 모델에 포함시켜 로지스틱 회귀 분석을 시행하였다. 교정 12 개월에서의 따라 잡기 성장 실패에 독 립적으로 영향을 미치는 요소는 출생 체중 $\mathrm{Z}$ 점수 $(P<0.001)$ 와 신 생아 집중 치료실 입원기간 $(P=0.007)$ 이었다. 출생 체중 $Z$ 점수의 따라 잡기 성장 실패에 대한 대응비(odds ratio)는 2.88로, 이는 출생 체중 Z 점수가 1 감소할수록 따라 잡기 성장이 실패할 위험 이 2.9 배 증가함을 의미하였다. 신생아 집중 치료실 입원기간의 따 라 잡기 성장 실패에 대한 대응비는 1.02 로, 이는 신생아 집중 치 료실 입원기간이 1 일 증가할수록 교정 나이 12 개월에서 따라 잡 기 성장을 실패할 위험이 1.02 배 증가함을 의미하였다. 교정 나이 24 개월까지 21명이 외래 추적 관찰에서 탈락되어, 82명(전체 환자 의 $79.6 \%$ )을 대상으로 로지스틱 회귀 분석을 시행하였다. 교정 나 이 24개월에서의 따라 잡기 성장 실패에 영향을 미치는 독립적인 인자는 출생 체중의 Z 점수뿐이었다 $(P<0.001)$. 출생 체중 Z 점수 의 교정 나이 24개월에서의 따라 잡기 실패에 대한 대응비는 2.98 로, 이는 출생 체중 Z 점수가 1 감소할수록 교정 나이 24개월에서 따라 잡기 성장을 실패 위험이 2.98였다(Table 3).

\section{4. 출생 체중 Z 점수와 교정 나이 12 개월 또는 24 개월에서의 체 중 Z 점수와의 상관 관계}

출생 체중의 Z 점수와 교정 나이 12 개월과 24 개월의 체중의 Z 점수는 각각 의미 있는 양의 상관 관계를 보였다(Figure 2) (Fig-

Table 2. Clinical Characteristics of Mothers

\begin{tabular}{llcc}
\hline Variables & SGA $(\mathrm{n}=34)$ & AGA $(\mathrm{n}=69)$ & $P$-value \\
\hline Preeclampsia & $17(50 \%)$ & $7(10.1 \%)$ & $<0.001$ \\
Multiple pregnancy & $12(35.3 \%)$ & $19(27.5 \%)$ & 0.420 \\
Maternal age & $33.08 \pm 3.77$ & $32.61 \pm 3.98$ & 0.751 \\
\hline
\end{tabular}

Abbreviations: SGA, small for gestational age; AGA, appropriate for gestational age.

Table 3. Logistic Regression Analysis of Determinants for Catch Up Growth at 12 and 24 months Corrected Age

\begin{tabular}{lccc}
\hline & S.E & $P$-value & Adjusted OR \\
\hline At 12 months CA & & & \\
$\quad$ Days of hospitalization & 0.007 & 0.007 & 0.980 \\
$\quad$ Birth weight z-score & 0.254 & 0.000 & 2.884 \\
$\begin{array}{l}\text { At 24 months CA } \\
\quad \text { Birth weight z-score }\end{array}$ & 0.284 & 0.000 & 2.977 \\
\hline
\end{tabular}

Abbreviations: CA, corrected age; S.E, standard error; Adjusted OR, adjusted odds ratio. ure 2A: $P<0.001$, Figure 2B: $P<0.001)$

\section{5. 교정 나이 12 개월과 24 개월에서의 따라 잡기 성장 실패의 예 측 도구로서 출생 체중 $\mathrm{Z}$ 점수의 진단적 가치}

출생 체중 Z 점수가 교정 나이 12 개월과 24 개월에서의 따라 잡 기 성장 실패를 예측할 수 있는 인자로서의 진단적 가치를 분석하 기 위해 receiver operating characteristic (ROC) 곡선을 그려 역 치 값을 구하였다. 교정 나이 12 개월에서 따라 잡기 성장 실패를 예측할 수 있는 출생 체중 Z 점수의 역치 값은 0.41 이었고, 출생 체 중 Z 점수가 0.41 보다 낮을 때 교정 나이 12 개월에서 따라 잡기 성장 실패를 예측하는 민감도(sensitivity)는 $71 \%$, 특이도(specificity)는 73\%이었다(Figure 3A). 교정 나이 24개월에서 따라 잡 기 성장 실패를 예측할 수 있는 출생 체중 Z 점수의 역치 값은 -0.91 이었고, 출생 체중 Z 점수가 -0.91 보다 낮을 때 교정 나이 24 개월에서 따라 잡기 성장 실패를 예측하는 민감도는 $80 \%$, 특이 도는 61\%이었다(Figure 3B).

\section{6. 따라 잡기 성장 실패군에서 고열량 영양 보조의 효과}

따라 잡기 성장 실패군에서 소아소화기영양분과 외래를 추적
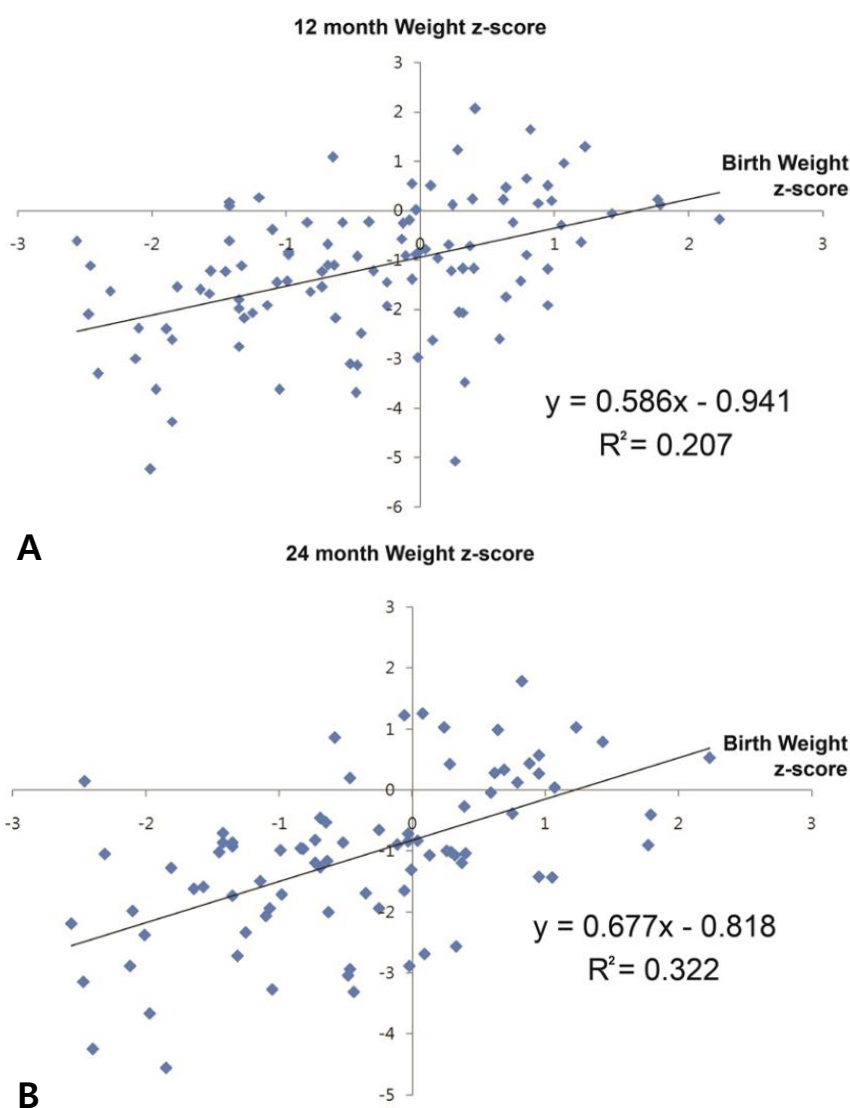

Figure 2. Correlation between birth weight z-score and weight z-score at 12 months (A) and 24 months (B) corrected age. 

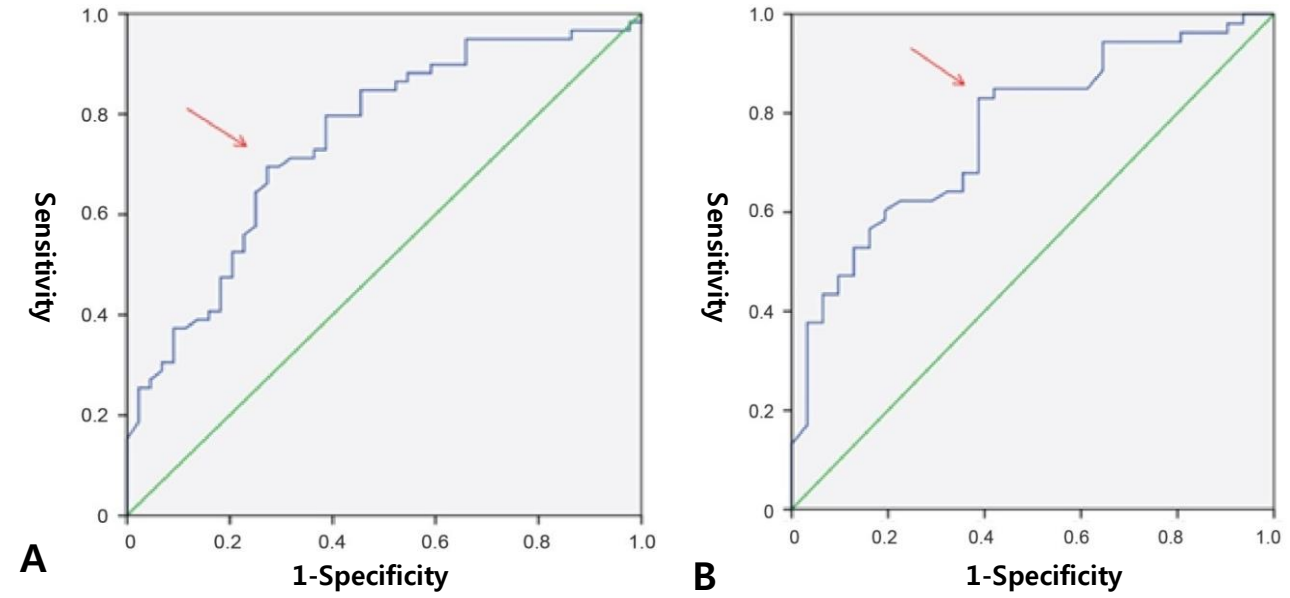

Figure 3. Receiver operating characteristic curve of birth weight z-score for the prediction of catch-up growth failure at 12 months (A) and 24 months (B) corrected age.

Table 4. Clinical Characteristics of the Group that received Nutritional Support and the Group That Did Not Receive Nutritional Support

\begin{tabular}{|c|c|c|c|}
\hline Variables & $\begin{array}{l}\text { Nutritional support group } \\
\qquad(\mathrm{n}=16)\end{array}$ & $\begin{array}{l}\text { No nutritional support group } \\
\qquad(\mathrm{n}=\mathbf{3 0})\end{array}$ & $P$-value \\
\hline Birth weight(g) & $1,000 \pm 446$ & $1,210 \pm 384$ & 0.26 \\
\hline Gestational age (wks) & $30 \pm 3$ & $29 \pm 3$ & 0.29 \\
\hline SGA & $9(56 \%)$ & $15(50 \%)$ & 0.26 \\
\hline Days of hospitalization at the NICU & $75.25 \pm 50.04$ & $60.34 \pm 37.41$ & 0.23 \\
\hline The number of readmissions after discharge from the NICU & $5(31 \%)$ & $4(13 \%)$ & 0.03 \\
\hline
\end{tabular}

Abbreviations: SGA, small for gestational age; NICU, neonatal intensive care unit.

관찰하면서 고열량 영양 지원을 해주었을 때 따라 잡기 성장을 개 선시킬 수 있는지 알아보기 위해, 교정 나이 12개월, 혹은 24개월 에서 체중이 10 백분위 수 미만인 따라 잡기 성장에 실패한 미숙 아들을 대상으로 고열량 영양 지원 여부에 따라 영양 지원군과 비 지원군 간에 교정 나이 12 개월과 24 개월 사이에 체중의 Z 점수의 변화에 유의한 차이가 있는지를 반복 분산 측도 분석(repeated measure ANOVA)을 사용하여 알아보았다. 따라 잡기 성장에 실 패한 미숙아들은 총 46 명이었고 이 중에 영양 지원군은 16 명, 비 지원군은 30 명이었다.

영양 지원군과 비지원군 간에 재태 주수, 출생 체중, 출생 시 SGA 여부, 신생아 집중 치료실 재원일수에는 통계적으로 유의한 차이가 없는 비교적 균일한 집단이었다. 다만 신생아 집중 치료실 퇴원 이후 5일 이상 재입원하는 횟수가 영양 지원군에서 더 높았 으며, 이는 통계적으로 유의하였다(Table 4). 재입원한 원인으로 영양 지원군에서는 $31 \%$ 인 5 명이 호흡기계 감염으로 입원 치료를 받았으며, 영양 비지원군에서는 $13 \%$ 인 4 명 중에서 3 명이 호흡기 계 감염, 1 명이 소화기계 감염으로 5 일 이상의 입원 치료를 받았 다. 영양 지원군과 비지원군 모두 교정 나이 12 개월에 비해 24개월 에 체중의 Z 점수가 증가하는 소견을 보였지만 영양 지원군이 비
지원군에 비해 교정 나이 12 개월과 24 개월 사이에 체중의 Z 점수 가 더 유의하게 증가하였다(Figure 4).

\section{고찰}

본 연구의 결과는 출생 체중의 $\mathrm{Z}$ 점수가 낮을 수록 교정 나이 12 개월과 24개월에서의 따라 잡기 성장이 실패할 위험이 높음을 보여주었고, 출생체중의 Z 점수가 교정 나이 12 개월과 24 개월에서 의 따라 잡기 성장의 성공 또는 실패 여부를 예측할 수 있는 인자 가 될 수 있음을 보여주었다. 또한 교정 나이 12 개월에서 따라 잡 기 성장에 실패한 미숙아들에게 소아 소화기 영양 클리닉을 통해 고열량 영양 지원을 해주었을 때 영양 지원을 해주지 않았을 경우 에 비해 교정나이 12 개월에서 24 개월 사이의 체중이 유의하게 증 가함을 보여주었다.

Altigani 등 21)은 저출생 체중아의 성장에서 출생 후 첫 24 주 동 안 따라 잡기 성장이 많이 이루어 진다고 하였다. 또한, Hack 등22) 에 의하면 극소 저체중 출생아의 성장 곡선은 영아기와 초기 학동 기까지 따라 잡기 성장이 이루어져서 8세경이면 체중, 키가 정상 

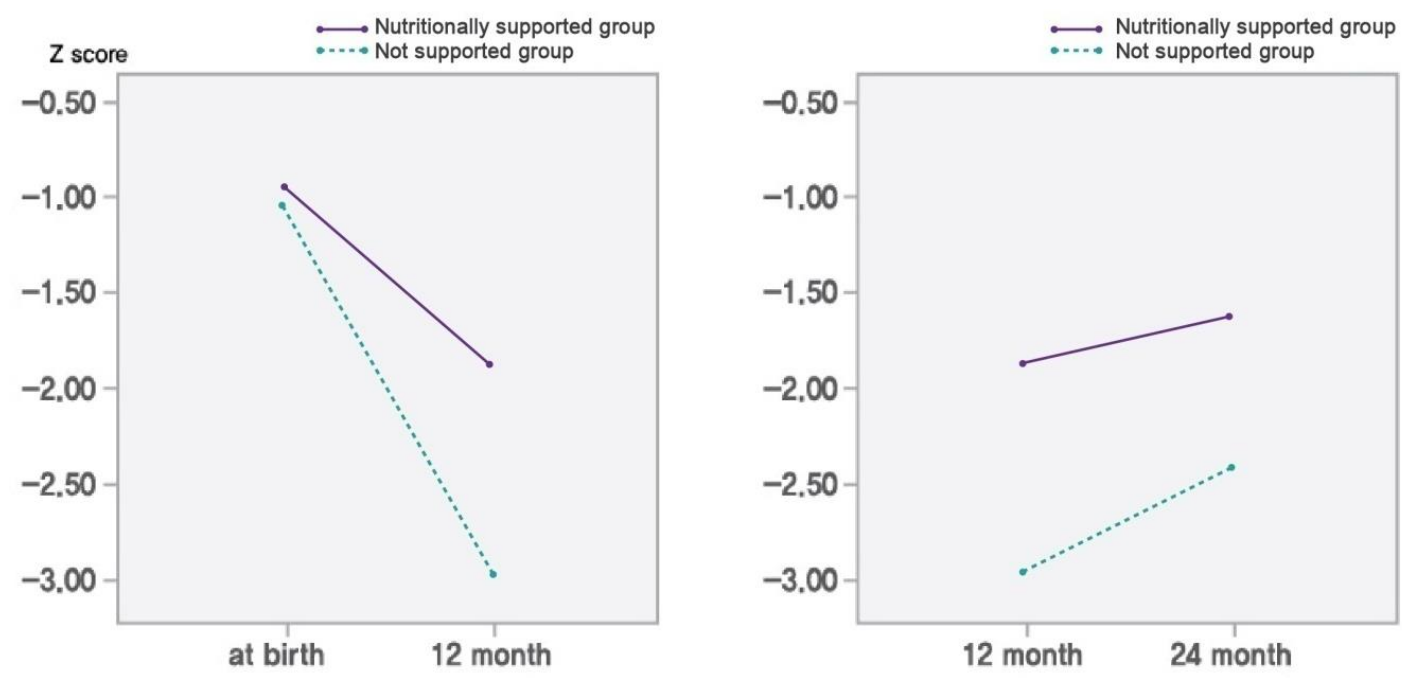

Figure 4. The changes in the weight z-score between 12 and 24 months corrected age according to whether high-calorie nutritional support was provided in preterm infants with failed catch-up growth at 12 months corrected age.

신생아 성장 곡선의 50 백분위수에 도달한다고 하였다.

Lei 등13)은 적정 체중아에 비해 부당 경량아인 경우에 따라 잡 기 성장에 실패할 확률이 높아 $22.4 \%$ 에서는 따라 잡기 성장에 실 패하여 영아기에는 감염 위험이 높고, 7세까지 성장 지연이 동반되 며, 지능 지수가 낮다고 보고한 바 있다. 또한 이에 비해 지나치게 따라 잡기 성장에 빨리 도달한 경우인 $8.9 \%$ 에서는 비만, 혈압 상 승의 위험도 및 대사 증후군의 위험도가 높음을 보고한 바 있단).

따라서 본 연구에서는 교정 나이 24개월까지의 따라 잡기 성장 성공 또는 실패 여부가 그 이후의 성장에 중요한 지표가 될 수 있 으며, 이 시기까지 적절한 따라 잡기 성장을 이루는 것이 장기적인 성장에 중요하다는 점에 착안하였다.

본 연구에서 $\mathrm{AGA}$ 군과 $\mathrm{SGA}$ 군 간에 주요한 신생아기 합병증 (NEC, BPD) 및 임신 나이, 완전 경장 영양 도달시점, 신생아 집중 치료실 입원 기간에 큰 차이가 없었음에도, AGA 군과 SGA군간에 따라 잡기 성장을 실패하는 비율은 통계적으로 유의한 차이가 있 었다(Table 1).

일반적으로 SGA군을 symmetric SGA군과 asymmetric SGA군 으로 나누어 분석하기도 한다. Symmetric SGA는 임신 1,2 분기 에 영향을 받아 출생 시 체중, 키, 두위가 모두 10 백분위 미만인 경 우이며 유전자 이상 혹은 주요 기형을 동반하거나 선천 감염을 동 반한 경우가 많은 반면, asymmetric SGA는 주로 임신 3분기 이후 부터 영향을 받아 두위의 성장은 보존되는 경우로, symmetric $\mathrm{SGA}$ 군에서 따라 잡기 성장이 더욱 힘들다는 것이 알려져 있다23). 그러나 유전자 이상 혹은 주요한 기형을 동반한 경우를 제외한다 면, 두 군간에 따라 잡기 성장에 큰 차이가 없다는 연구도 보고된 바 있달). 본 연구에서 Symmetric SGA군은 전체 SGA 중 16명
(48.5\%) 였고, asymmetric SGA군은 전체 SGA 중 17명(51.5\%) 였다. Symmetric SGA군에서 교정 12개월째 체중의 따라 잡기 성 장을 한 경우는 4 명 $(25 \%)$ 이었으며, asymmetric SGA 군에서 교 정 12 개월째 체중의 따라 잡기 성장을 한 경우는 5명 $(29 \%)$ 이었 다. Asymmetric SGA 군에서 따라 잡기 성장에 성공하는 비율이 symmetric 군에 비해 높았으나, 통계적으로는 유의하지 않았다 $(P=0.24)$. 이 결과는 본 연구에서 유전자 이상이나 주요 기형이 있 는 환자를 연구 대상에서 제외했기 때문이라고 추정하였다.

주요한 신생아기 합병증들을 포함한 교란 변수들의 영향을 보 정하여, 로지스틱 회귀 분석을 하였을 때 미숙아에서 출생 체중 Z 점수가 1 감소할 때 따라 잡기 성장을 실패할 위험도가 교정나이 12 개월에는 2.88 배, 교정나이 24 개월에는 2.98 배 증가하였다. 또 한 교정 12 개월째까지의 따라 잡기 성장에는 신생아 집중 치료실 입원 기간이 영향을 미치는 것으로 보이나(OR 0.98, $P=0.007)$, 교 정나이 24 개월에는 영향을 주지 않는 것으로 분석되어, 출생 체중 $\mathrm{Z}$ 점수가 따라 잡기 성장 성공 또는 실패를 예측하는 유용한 척도 로 사용될 수 있음을 알 수 있었다.

$\mathrm{Z}$ 점수의 따라 잡기 성장 실패를 예측하는 지표로서의 진단적 유용성을 파악하기 위하여 ROC 곡선을 이용하여 분석해 보았을 때, 출생체중 Z 점수가 0.41 미만인 경우 교정 나이 12 개월에서의 따라 잡기 성장 실패 예측의 민감도는 0.71 , 특이도는 0.73 이었으 며, 출생 체중 Z 점수가 -0.91 미만인 경우 교정 24개월에서의 따 라 잡기 성장 실패 예측의 민감도는 0.90 , 특이도는 0.61 이었다. 출 생 체중 Z 점수 0.73 과 -0.91 은 모두 적정 체중아에 해당하는 값 들이다. 부당 경량아의 기준은 출생 체중 Z 점수로는 -1.29 가 된다 ${ }^{18)}$. 따라서 이 결과는 미숙아들의 경우 적정 체중인 경우에도 교 
정 12 개월과 24개월째에 따라 잡기 성장에 실패할 위험성이 있다 는 것을 시사하는 소견으로 생각되었다.

평균적으로 $\mathrm{SGA}$ 는 $\mathrm{AGA}$ 보다 열량이 약 $4 \mathrm{kcal} / \mathrm{kg} / \mathrm{day}$ 가 더 필요한 것으로 알려져 있다 ${ }^{25}$. 본 연구에서는 따라 잡기 성장 실패 군을 대상으로 소아 소화기 영양 분과에서 추적 관찰을 하며 고열 량 영양 지원을 해주었으며, 영양 지원군과 영양 비지원군은 재 입 원 횟수 이외에는 임상적인 특성에 큰 차이가 없는 비교적 유사한 집단임에도 불구하고, 영양 지원 여부에 따라 교정 나이 12 개월 이후의 체중 증가 개선에 긍정적인 영향을 줌을 알 수 있었다. 따 라서 미숙아 중에서도 SGA에서 더욱 적극적으로 영양 지원 클리 닉을 통해 추적 관찰을 하며 영양 상담 및 적절한 영양 지원을 하 는 것이 최종적인 따라 잡기 성장 성공에 도움이 될 것이라고 결론 내릴 수 있었다.

본 연구의 강점은 SGA에서 임신 나이에 비해 출생 체중이 적게 나가는 정도를 계측하여 이에 따라 잡기 성장에 실패할 위험도를 산술적으로 나타냈다는 점이다. 따라서 외래에서 추적 관찰을 하 는 환자들에서 출생 체중 $\mathrm{Z}$ 점수를 산출한 후 개인의 따라 잡기 성장 실패에 대한 위험도를 계산할 수 있다. 또한 교정 나이 12개 월까지 따라 잡기 성장에 실패한 환자에서 소아 소화기 영양 분과 의 추적 관찰을 통해 고열량 영양 지원을 시행한 경우 이후의 체중 증가 향상에 도움이 될 수 있으므로, 적극적으로 정기적인 영양 상담을 하고 필요 시 적절한 영양 지원을 하는 것이 중요할 것으로 생각되었다.

본 연구의 한계는 단일 기관에서의 후향적 연구로, 의무 기록 고 찰로만 자료를 모아서, 교정나이 12 개월 또는 24 개월의 전후 30 일 이내로 측정된 체중으로 분석을 하였다는 점이다. 두 번째로 외래 관찰 중에 모든 환자를 대상으로 12 개월과, 24 개월째의 키와 머리 둘레에 대한 측정이 이루어지지 않아서 키의 따라 잡기 성장에 대 한 결과를 논문에 반영하지 못한 것을 한계로 지적할 수 있다. 세 번째로 퇴원 후 소아 소화기 영양 분과를 추적 관찰하지 않은 환 자에서는 영양 상태를 정확히 알 수 없다는 점이다. 소아 소화기 영양 분과에서 추적 관찰한 미숙아들은 주로 신생아 집중 치료실 입원 기간이나 퇴원 후에 체중 증가가 더뎠던 환자들로 고열량 영 양 지원의 효과를 이들을 대상으로만 본 것은 선정 편향(selection bias)이 개입 되었을 가능성이 있어, 이 점도 이 연구의 한계 라고 할 수 있다.

향후 연구해야 할 과제로 본 연구 대상이었던 미숙아 SGA군과 $\mathrm{AGA}$ 군을 보다 장기적으로 청소년기까지 관찰을 하며 체중, 키 및 체질량 지수를 연속적으로 조사하는 것이 따라 잡기 성장 실패 고 위험군의 성장 발달을 이해하는데 도움을 줄 것이다. 특히 미숙아 $\mathrm{SGA}$ 군의 경우 따라 잡기 성장에 도달하였더라도 혈압과 혈당 등 의 정기적인 검진을 시행하여, 대사증후군의 발생에 대해 꾸준히 관찰 및 이에 대한 관리를 하는 것이 중요할 것으로 생각된다.

\section{REFERENCES}

1) Lim JW, Jun NL, Kim KA, Kim AR, Kim KS, Pi SY. Postnatal catch-up growth of very low birth weight infants. J Korean Soc Neonatol 2002;9:1-11.

2) Qvigstad E, Verloove-Vanhorick SP, Ens-Dokkum $\mathrm{MH}$, Schreuder AM, Veen S, Brand R, et al. Prediction of height achievement at five years of age in children born very preterm or with very low birth weight: continuation of catch-up growth after two years of age. Acta Paediatr 1993;82:444-8.

3) Niklasson A, Engstrom E, Hard AL, Wikland KA, Hellstrom A. Growth in very preterm children: a longitudinal study. Pediatr Res 2003;54:899-905.

4) Hokken-Koelega AC, De Ridder MA, Lemmen RJ, Den Hartog H, De Muinck Keizer-Schrama SM, Drop SL. Children born small for gestational age: do they catch up? Pediatr Res 1995;38: 267-71.

5) Hirata T, Bosque E. When they grow up: the growth of extremely low birth weight $(<$ or $=1000$ gm) infants at adolescence. $\mathrm{J}$ Pediatr 1998;132:1033-5.

6) Fewtrell MS, Morley R, Abbott RA, Singhal A, Stephenson T, MacFadyen UM, et al. Catch-up growth in small-for-gestational-age term infants: a randomized trial. Am J Clin Nutr 2001;74:516-23.

7) Darendeliler F, Coban A, Bas F, Bundak R, Disci R, Sukur M, et al. Catch-up growth in appropriate- or small-for-gestational age preterm infants. Turk J Pediatr 2008;50:207-13.

8) Casey PH, Kraemer HC, Bernbaum J, Yogman MW, Sells JC. Growth status and growth rates of a varied sample of low birth weight, preterm infants: a longitudinal cohort from birth to three years of age. J Pediatr 1991;119:599-605.

9) Soto N, Bazaes RA, Pena V, Salazar T, Avila A, Iniguez G, et al. Insulin sensitivity and secretion are related to catch-up growth in small-for-gestational-age infants at age 1 year: results from a prospective cohort. J Clin Endocrinol Metab 2003;88:3645-50.

10) Jung MK, Song JE, Yang S, Hwang IT, Lee HR. Catch up growth in children born small for gestational age by corrected growth curve. Korean J Pediatr 2009;52:984-90.

11) Knops NB, Sneeuw KC, Brand R, Hille ET, den Ouden AL, Wit $\mathrm{JM}$, et al. Catch-up growth up to ten years of age in children born very preterm or with very low birth weight. BMC Pediatr 2005;5:26

12) Monset-Couchard $M$, de Bethmann O. Catch-up growth in 166 small-for- gestational age premature infants weighing less than 1,000 g at birth. Biol Neonate 2000;78:161-7.

13) Lei $X$, Chen $Y$, Ye J, Ouyang F, Jiang F, Zhang J. The optimal postnatal growth trajectory for term small for gestational age babies: a prospective cohort study. J Pediatr 2015;166:54-8. 
14) Brenseke B, Prater MR, Bahamonde J, Gutierrez JC. Current thoughts on maternal nutrition and fetal programming of the metabolic syndrome. J Pregnancy 2013;2013:368461.

15) Young T. Nutritional support and bronchopulmonary dysplasia. J Perinatol 2007;27:S75-S8.

16) Hintz SR, Kendrick DE, Stoll BJ, Vohr BR, Fanaroff AA, Donovan $\mathrm{EF}$, et al. Neurodevelopmental and growth outcomes of extremely low birth weight infants after necrotizing enterocolitis. Pediatrics 2005;115:696-703.

17) Fenton TR, Kim JH. A systematic review and meta-analysis to revise the Fenton growth chart for preterm infants. BMC Pediatr 2013;13:59.

18) Fenton TR, Sauve RS. Using the LMS method to calculate $\mathrm{z}$ scores for the Fenton preterm infant growth chart. Eur J Clin Nutr 2007;61:1380-5.

19) Grummer-Strawn LM, Reinold C, Krebs NF. Use of World Health Organization and CDC growth charts for children aged 0-59 months in the United States. MMWR Recomm Rep 2010; 59:1-15.
20) Ofek Shlomai N, Reichman B, Lerner-Geva L, Boyko V, Bar-Oz B. Population-based study shows improved postnatal growth in preterm very-low-birthweight infants between 1995 and 2010. Acta Paediatr 2014;103:498-503.

21) Altigani M, Murphy JF, Newcombe RG, Gray OP. Catch up growth in preterm infants. Acta Paediatr Scand Suppl 1989;357: 3-19.

22) Hack M, Weissman B, Breslau N, Klein N, Borawski-Clark E, Fanaroff AA. Health of very low birth weight children during their first eight years. J Pediatr 1993;122:887-92.

23) Dashe JS, McIntire DD, Lucas MJ, Leveno KJ. Effects of symmetric and asymmetric fetal growth on pregnancy outcomes. Obstet Gynecol 2000;96:321-7.

24) Bocca-Tjeertes I, Bos A, Kerstjens J, de Winter A, Reijneveld S. Symmetrical and asymmetrical growth restriction in pretermborn children. Pediatrics 2014;133:e650-6.

25) Sulkers EJ, Lafeber HN, Degenhart HJ, Lindemans J, Sauer PJ. Comparison of two preterm formulas with or without addition of medium-chain triglycerides (MCTs). II: Effects on mineral balance. J Pediatr Gastroenterol Nutr 1992;15:42-7. 